ACCEPTED MANUSCRIPT

\title{
Evolution of nanomechanical properties and crystallinity of individual titanium dioxide nanotube resonators
}

To cite this article before publication: Stefano Stassi et al 2017 Nanotechnology in press https://doi.org/10.1088/1361-6528/aaa46c

\section{Manuscript version: Accepted Manuscript}

Accepted Manuscript is "the version of the article accepted for publication including all changes made as a result of the peer review process, and which may also include the addition to the article by IOP Publishing of a header, an article ID, a cover sheet and/or an 'Accepted Manuscript' watermark, but excluding any other editing, typesetting or other changes made by IOP Publishing and/or its licensors"

This Accepted Manuscript is @ 2017 IOP Publishing Ltd.

During the embargo period (the 12 month period from the publication of the Version of Record of this article), the Accepted Manuscript is fully protected by copyright and cannot be reused or reposted elsewhere.

As the Version of Record of this article is going to be / has been published on a subscription basis, this Accepted Manuscript is available for reuse under a CC BY-NC-ND 3.0 licence after the 12 month embargo period.

After the embargo period, everyone is permitted to use copy and redistribute this article for non-commercial purposes only, provided that they adhere to all the terms of the licence https://creativecommons.org/licences/by-nc-nd/3.0

Although reasonable endeavours have been taken to obtain all necessary permissions from third parties to include their copyrighted content within this article, their full citation and copyright line may not be present in this Accepted Manuscript version. Before using any content from this article, please refer to the Version of Record on IOPscience once published for full citation and copyright details, as permissions will likely be required. All third party content is fully copyright protected, unless specifically stated otherwise in the figure caption in the Version of Record.

View the article online for updates and enhancements. 


\section{Evolution of nanomechanical properties and}

\section{crystallinity of individual titanium dioxide nanotube}

\section{resonators}

Stefano Stassi ${ }^{\mathrm{a}, \mathrm{b}, *, *}$, Andrea Lamberti ${ }^{\mathrm{a}, \mathrm{b}, \mathrm{*}}$, Ignazio Roppolo $^{\mathrm{b}}$, Alberto Casu ${ }^{\mathrm{c}}$, Stefano Bianco ${ }^{\mathrm{a}}$, Davíde Scaiola ${ }^{\mathrm{a}}$, Andrea Falqui ${ }^{\mathrm{c}}$, Candido Fabrizio Pirri ${ }^{\mathrm{a}, \mathrm{b}}$, Carlo Ricciardi ${ }^{\mathrm{a}}$

${ }^{a}$ Department of Applied Science and Technology, Politecnico di Torino, Corso Duca degli Abruzzi 24, 10129 Torino, Italy

${ }^{\mathrm{b}}$ Center for Sustainable Future Technologies, Istituto Italiano di Tecnologia, Corso Trento 21, Torino, 10129 Italy

${ }^{\mathrm{c}}$ King Abdullah University of Science and Technology (KAUST), Biological and Environmental Sciences and Engineering (BESE) Division, Nabla Lab, Thuwal 23955-6900, Saudi Arabia.

${ }^{*}$ These authors equally contributed to the work

*Corresponding authors: stefano.stassi@polito.it

\section{ABSTRACT}

Herein a complete characterization of single $\mathrm{TiO}_{2}$ nanotube resonator was reported for the first time.

The modal vibration response analysis allows a non-invasive indirect evaluation of the mechanical properties of the $\mathrm{TiO}_{2}$ nanotube. The effect of post-grown thermal treatments on nanotube mechanical properties was investigated and carefully correlated to the chemico-physical parameters evolution. The Young's modulus of $\mathrm{TiO}_{2}$ nanotube linearly rises from $57 \mathrm{GPa}$ up to $105 \mathrm{GPa}$ for annealing at $600^{\circ} \mathrm{C}$ depending on the compositional and crystallographic evolution of the 
nanostructure. Considering the growing interest in single nanostructure devices, the reported findings allow a deeper understanding of the properties of individual titanium dioxide nanotubes extrapolated from their standard arrayed architecture.

KEYWORDS: nanomechanical resonator, $\mathrm{TiO}_{2}$ nanotubes, Young's modulus, crystallization, mechanical properties.

\section{INTRODUCTION}

Since the first report of Grimes et al.[1] in 2001, the growth of self-organized $\mathrm{TiO}_{2}$ nanotube (NT) arrays by electrochemical anodic oxidation of titanium surface has increasingly attracted great scientific interest in recent years owing to their exceptional properties, peculiar arrangement, and potential for almost every research field.

Vertically-oriented $\mathrm{TiO}_{2} \mathrm{NT}$ arrays can provide high surface area and superior electron transport properties that, coupled to the highly ordered architecture, allow their effective exploitation for several class of devices such as solar cells (dye-sensitized, solid state and perovskites solar cell),[25] water splitting, [6, 7] energy storage (batteries and supercapacitors), [8, 9] sensors (UV, gas, molecule, or $\mathrm{pH}),[10-12]$ electrocromic devices,[13] photocatalytic reactors,[14] memristors,[15] cell adhesion substrates, [16] photonic devices [17] and many others.[18]

Moreover, their as-grown amorphous nature permits subsequent crystallization in the desired polycrystalline phase, according to the application, by thermal or water-assisted post processing treatments.[19, 20] Besides, the morphology was shown to have a strong dependence on the crystallization procedure. Indeed, thermal treatments induce an increase of the crystallite size and the formation of grain boundaries along the tube wall, while wet approaches can lead to a transformation from nanotubes to porous nanorod. 
Apart from the electronic and chemical properties, these structural variations can strongly influence the mechanical properties of the $\mathrm{TiO}_{2}$ nanotubes, whose variation is even more important considering the strong interest for the application of metal-oxide nanostructure in flexible devices.[21-23]

Generally nanostructured materials present quite different mechanical properties when compared with their bulk counterparts.[24, 25] So far mechanical properties of $\mathrm{TiO}_{2}$ nanotubes have been investigated only with direct compressive measurements. Most of the analyses were performed on nanotubes array by means of nanoindentation approach, where a rigid nanometric tip is pressed on the top surface of the material while the applied force and deformation of the nanotubes are recorded[26-31]. Young's modulus values obtained with this technique were very scattered, ranging from 36-43 $\mathrm{GPa}[28]$ up to $80-95 \mathrm{GPa}[31]$, because of the non-uniform shape of the nanostructured arrays. As well, only few works measured the mechanical properties of individual $\mathrm{TiO}_{2}$ nanotubes[32, 33]. Shokuhfar et al. compressed individual nanotubes up to fracture with the tip of an atomic force microscope microcantilever inside a transmission electron microscope (TEM)[32]. These experiments lead to Young's modulus in the range of 23-44 GPa, comparable with the results obtained from the arrays analysis, but showing a higher variability determined by the slight difference in nanotube geometry. A similar approach was used by Kang et al. performing compressive tests in a TEM using a nanoindentation holder and obtaining significantly lower values (2.2-9.4 GPa)[33]. The main limitation of both approaches is that, being direct invasive methods, they strongly depend on the experimental set-up and analyze only the compressive properties of the material. Furthermore, the samples are usually brought to fracture and destroyed, limiting the possibility of parametric analysis of the mechanical properties, such as their dependence on temperature, atmosphere or crystallization phase.

In this work, we investigated the Young's modulus of single $\mathrm{TiO}_{2}$ nanotubes with a non-invasive indirect approach based on modal vibration response analysis of the inorganic nanostructure. Treacy et al. were the first to apply this method to measure Young's modulus of individual 
nanostructures[34]. They evaluated the vibration of individual free-standing carbon nanotubes induced by thermal motion by TEM imaging and unveiled the elastic properties measuring their resonance frequencies. Similarly, here we calculate Young's modulus from the measurements of resonance frequency of suspended $\mathrm{TiO}_{2}$ nanotubes. Moreover, for the first time the mechanical properties of single nanotubes were measured after different thermal treatments, evaluating their variation induced by crystalline structure evolution and organic compounds removal.

\section{METHODS}

The nanotubes were prepared by anodic oxidation of titanium foils (thickness $250 \mu \mathrm{m}, 99.96 \%$ purity, Goodfellow) cleaned by ultra-sonication in acetone and soft $\mathrm{HF}$ etching to remove native oxide. The electrochemical process was conducted at $25^{\circ} \mathrm{C}$ in an electrolytic solution containing 0.5 wt. $\% \mathrm{NH}_{4} \mathrm{~F}$ and 2.5 wt.\% deionized water in ethylene glycol, using a platinum sheet as counter electrode (thickness $250 \mu \mathrm{m}, 99.99 \%$ purity, Goodfellow). The anodization time was fixed to 30 minutes working under continuous stirring with a constant voltage of $60 \mathrm{~V}$ in order to obtain nanotubes with length of approximately $10 \mu \mathrm{m}$. The samples were then rinsed in DI-water, dried and detached by ultra-sonication in ethanol for 5 minutes. Then, a droplet of the solution containing detached single nanotubes was spread on a silicon die presenting a rectangular opening over the whole wafer thickness.

Vibration analysis was performed with a Laser Doppler Vibrometer (LDV) system (MSA-500, Polytec Gmbh). The LDV system is composed by an optical microscope with objective up to $100 \mathrm{X}$ used to find the suspended nanotubes arranged on the edge of the opening and then to focus the laser on their tip. The sample was mounted on a piezodisk used for the actuation, inside a vacuum chamber, evacuated by a membrane and a turbomolecular pump (MINI-Task System, Varian Inc. Vacuum Technologies) up to a vacuum level of $2 * 10^{-7}$ mbar. The sample was mechanically actuated by sending an electrical signal to the piezodisk composed of a combination of sine waves with the 
frequencies of the range under investigation. The laser light reflected by the sample, coupled with the tip displacement velocity of the nanotube, exploits a shift in frequency because of Doppler effect. Then, from the measurement of the laser frequency shift, the system computes the vibration velocity and amplitude of the sample as function of the actuation frequency.

Differential scanning calorimetry (DSC) experiment was performed using a Netzsch DSC 204 F1 Phoenix instrument, equipped with a low temperature probe. The experiment was performed in air (20 $\mathrm{ml} / \mathrm{min}$ ), scanning the temperature range between $30^{\circ} \mathrm{C}$ and $600{ }^{\circ} \mathrm{C}$ with a temperature ramp rate of $1{ }^{\circ} \mathrm{C} / \mathrm{min}$ and 4 isothermal steps of 1 hour each $\left(150^{\circ} \mathrm{C}, 300^{\circ} \mathrm{C}, 450^{\circ} \mathrm{C}\right.$ and $\left.600^{\circ} \mathrm{C}\right)$ during the measurement. The same temperature program was used for thermogravimetric analysis (TGA), which was performed using a Netzsch TG 209 F1 Libra instrument.

Raman characterizations on few nanotubes bundles were performed with a Renishaw inVia Reflex micro-Raman spectrophotometer, equipped with a cooled CCD camera. Samples were excited at a 100x magnification with an $\mathrm{Ar}-\mathrm{Kr}$ laser source with a wavelength of $514.5 \mathrm{~nm}$.

High Resolution Transmission Electron Microscopy: High Resolution TEM (HRTEM) analysis was performed ex situ on a $300 \mathrm{kV}$ Cs Image corrected FEI Titan Cube microscope, studying the structural evolution of the $\mathrm{TiO}_{2}$ nanotubes against temperature after each ex situ heating step. The ex situ heating was performed in air using the Wildfire system by DENSsolutions, acquiring HRTEM images in the temperature range between RT (room temperature, i.e. $20^{\circ} \mathrm{C}$ ) and $450^{\circ} \mathrm{C}$. This was divided in $150^{\circ} \mathrm{C}$-wide steps and, for each step, a $150^{\circ} \mathrm{C}$-wide heating ramp with a $1{ }^{\circ} \mathrm{C} / \mathrm{min}$ rate was set; the target temperature was maintained for 3 minutes before fast decreasing the temperature to RT and proceeding with the HRTEM analysis. Initial temperatures (for T $>$ RT) were reached via fast "pre-heating" temperature ramps before starting the actual $1^{\circ} \mathrm{C} / \mathrm{min}$ heating ramps. The heating in air caused a progressive degradation of the MEMS chip in terms of overall cleanness of the thin film and of its mechanical stability, until a massive rupture of the film was observed at $450^{\circ} \mathrm{C}$, which made impossible any further heating. Thus, $450^{\circ} \mathrm{C}$ was deemed as the final temperature for ex situ heating experiments. 


\section{RESULTS AND DISCUSSION}

The anodic oxidation of titanium foils in an electrolytic solution containing $0.5 \mathrm{wt}, \% \mathrm{NH}_{4} \mathrm{~F}$ and 2.5 wt.\% deionized water in ethylene glycol results in the formation of the self-organized vertically oriented $\mathrm{TiO}_{2}$ nanotubes, as shown in Figure 1a. The selected anodization time and voltage lead to nanotubes with length of approximately $10 \mu \mathrm{m}$ and average inner diameter of $80 \mathrm{~nm}$. In order to obtain the desired suspended single nanotube, the experimental steps schematically represented in Figure 1b-e have been carried out. The as-grown NTs were rinsed in deionized water, dried and detached by ultra-sonication in ethanol for 5 minutes. A droplet of nanotube solution was dropped over a silicon die presenting a rectangular opening over the whole wafer thickness prepared by standard microfabrication technique based on $\mathrm{KOH}$ silicon wet etching[35]. Some of the single nanotubes spread over the whole surface with a certain amount arranged on the edge of the opening, as shown in the FESEM images reported in Figure 1f. Resonance frequency of the suspended nanotubes was evaluated as a function of the performed thermal treatments (see Figure 1g) by means of a Laser Doppler Vibrometer (LDV) which does not imply a direct measurement of the vibration amplitude, like in the classic optical lever technique, but exploits a Fast Fourier Transform approach[36]. Natural resonance frequencies of individual suspended nanotubes were measured on just spotted samples and then after each of 4 thermal treatments consisted of a heating ramp at $1{ }^{\circ} \mathrm{C} / \mathrm{min}$ and isothermal step of $1 \mathrm{~h}$ at $150,300,450$ and $600{ }^{\circ} \mathrm{C}$, respectively (Figure 2a). Since the nanotubes are randomly dispersed over the sample, they can arrange in position not perfectly perpendicular to the silicon edge, even if NTs with angle above $75^{\circ}$ were considered. The effect of the tilting angle of the suspended $\mathrm{TiO}_{2}$ nanotubes was evaluated by a finite element simulation (results in the Supporting Information) and resulted in a variation below $0.2 \%$ for angle up to $30^{\circ}$ with respect to the edge of the wafer. This variation is far below the frequency shifts induced by thermal annealing steps and thus was neglected in the following Young's modulus computation. 
a)

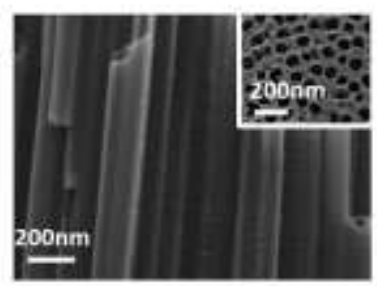

b)
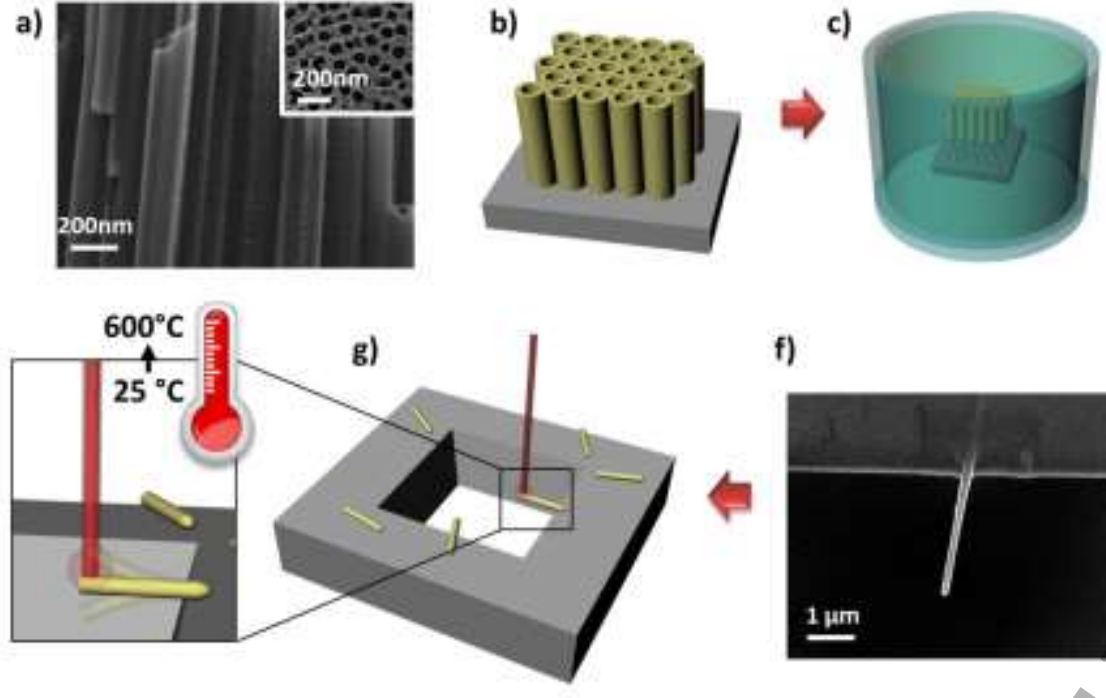

f)

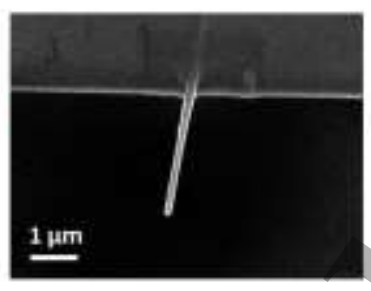

d)

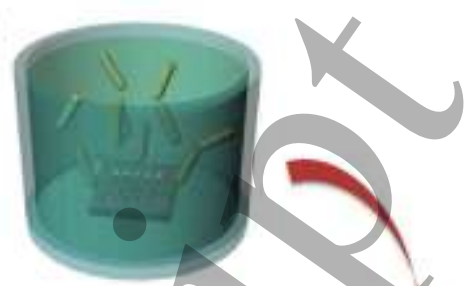

e)

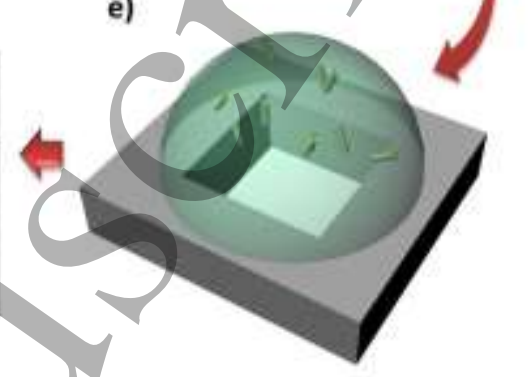

Figure 1. Scheme of the experimental procedure: cross section and top (in the inset) FESEM images of the as grown $\mathrm{TiO}_{2}$ NTs carpet (a), the NTs sample were then cut (b), immersed in aqueous solution (c) and sonicated to detach single nanotubes (d). The dispersion was dispensed on ad-hoc designed silicon chip and let dry overnight (e) resulting in single NTs arrange on the edge of the opening (f). The chip was mounted in the vibrometer set-up for resonating measurements (g).

Simplified continuum models from the Bernoulli-Euler beam theory were used to describe the motion of the suspended $\mathrm{TiO}_{2}$ nanotubes and to indirectly determine their elastic modulus from the natural resonance frequency. In the limit of small deformations, as well as negligible dumping effects and external forces, the equation describing the flexural motion of a beam (i.e. $\mathrm{TiO}_{2} \mathrm{NT}$ ) is:

$E I \frac{\partial^{4} u}{\partial x^{4}}+\rho A \frac{\partial^{2} u}{\partial t^{2}}=0(1)$

where $E$ indicates Young's modulus, $I$ is the moment of inertia of the beam cross-sectional area $A, u$ is the beam displacement and $\rho$ is the density of the beam material. Then, the natural frequency of the $n^{\text {th }}$ mode of vibration of the beam is: 
$f_{n}=\frac{\left(k_{n} L\right)^{2}}{2 \pi L^{2}} \sqrt{\frac{E I}{\rho A}}$

where $L$ is the beam length and $k_{n} L$ the eigenvalue for the $n^{\text {th }}$ mode depending on the boundary conditions applied to the model. In the case of single clamped beam like the nanotubes, the eigenvalues for the first two modes are $k_{1} L=1.875$ and $k_{2} L=4.694$. For a cylindrical tube of outside and inside radii $R_{o}$ and $R_{i}$ the moment of inertia is $I=\pi\left(R_{o}^{4}-R_{i}^{4}\right)$ and thus we can derive from equation 2 , the resonance frequency of the $n^{\text {th }}$ mode of vibration of the suspended $\mathrm{TiO}_{2}$ nanotube as[34]:

$f_{n}=\frac{\left(k_{n} L\right)^{2}}{4 \pi L^{2}} \sqrt{\frac{E\left(R_{o}^{2}+R_{i}^{2}\right)}{\rho}}$

Then measuring the modal vibration response is possible to indirectly estimate the Young's modulus of the NTs as:

$E=\left(\frac{4 \pi L^{2}}{\left(k_{n} L\right)^{2}}\right)^{2} \frac{f_{n}^{2} \rho}{\left(R_{o}^{2}+R_{i}^{2}\right)}$

From the measurement of the resonance frequencies and the geometrical features of the suspended $\mathrm{TiO}_{2}$ nanotubes (frequency dispersion presented in the S.I.), the Young's modulus was extracted with equation (4). A linear dependence of the stiffness of the nanotubes on the annealing temperature was found, with a variation from $57 \mathrm{GPa}$ on the as-synthesized samples to $105 \mathrm{GPa}$ on the samples treated at $600^{\circ} \mathrm{C}$ (Figure $2 \mathrm{~b}$ ). As expected both values are considerably below the bulky value of $282 \mathrm{GPa}[31]$. Annealing of the samples induces significantly transformation of the single nanotubes, because of both degradation organic synthesis residual products and crystallization of the samples. The Young's modulus of the single nanostructures were compared with the Young's modulus values of titanium nanotubes array sample investigated with nanoindentation approach (data from [31]). Even if the data were in the same range, the measurements performed with the vibration analysis returned less scattered values, because they are related to single nanotubes and they are not dependent on the bond among close-packed NTs like in the array. Besides, vibrational 
measurements represent a non-invasive and non-destructive approach, which, with respect to nanoindentation tests, removes the possibility of artifacts related to the tip by feedback control.
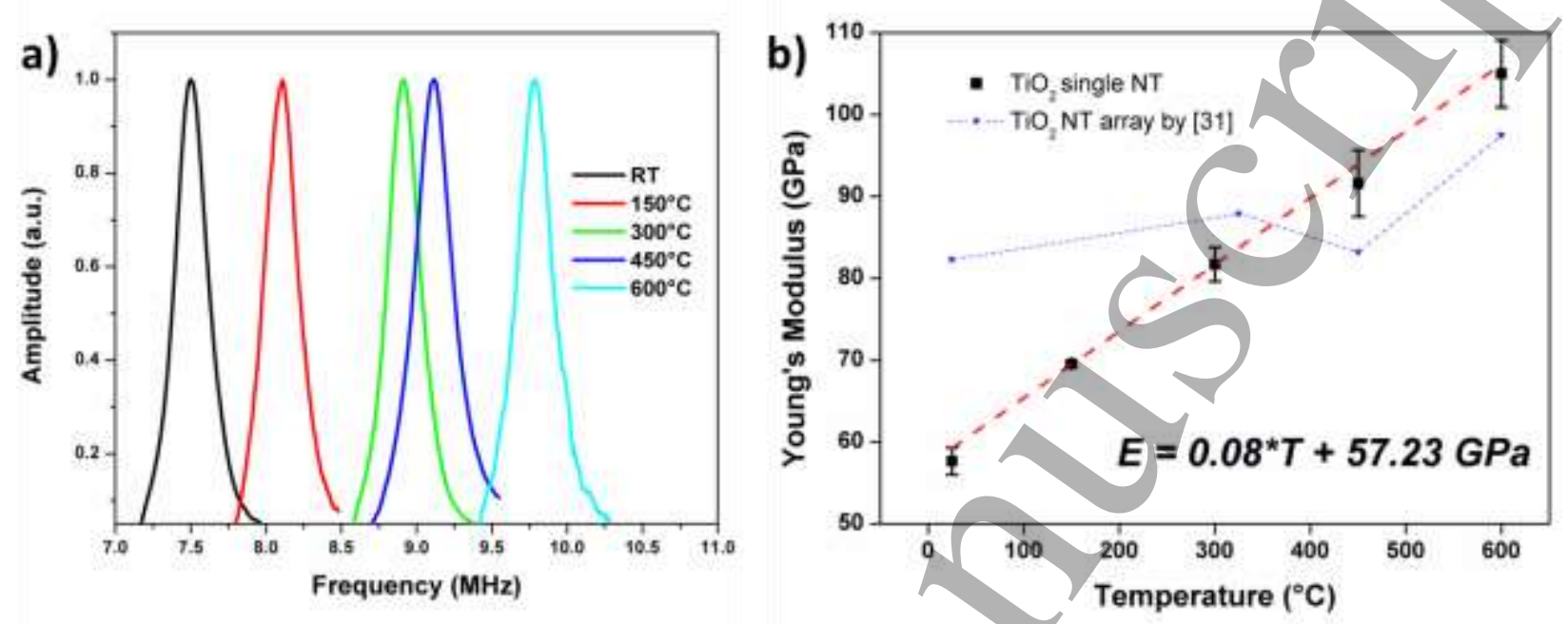

Figure 2. Nanomechanical analysis of suspended nanotubes. (a) Evolution of the first resonance mode of a suspended $\mathrm{TiO}_{2}$ nanotube after each heating step. The amplitude of the vibration spectra was normalized for a better comparison.

(b) Young's modulus of single $\mathrm{TiO}_{2}$ nanotubes/as function of heating step. Star represented literature value from[31] of Young's modulus of $\mathrm{TiO}_{2}$ nanotube array after different heating treatment

In order to explain the single $\mathrm{TiO}_{2}$ nanotube transformation induced by thermal annealing and the impact on their mechanical properties, chemico-physical characterizations were performed.

As-synthesized $\mathrm{TiO}_{2}$ nanotubes, detached from the titanium foil, were tested by means of differential scanning calorimetry (DSC) and thermogravimetric analysis (TGA) analysis. Both the analyses were performed with the same thermal treatment used for the individual suspended nanotubes. DSC analysis showed the presence of two exothermic peaks, centered at $255^{\circ} \mathrm{C}$ and at $363^{\circ} \mathrm{C}$ (Figure $3 \mathrm{a}$ ). The first one can be ascribed to the evaporation of the glycolated species formed in the reaction between oxidized titanium and ethylene glycol;[37] consequently in TGA (Figure 3b) we evidenced a first weight loss (around 1\%). The second one could be attributed both to the 
thermal crystallization of amorphous phase to anatase[38] and to dehydroxylation of $\mathrm{TiOH}$ to $\mathrm{TiO}_{2 .}$.[39] Condensation of hydroxyl groups led to a more important weight loss (around 5\%), as shown by TGA experiments. These results are in good agreement with what reported in literature, however Raman experiments were performed in over to get more detailed information regarding crystalline phase.

a)

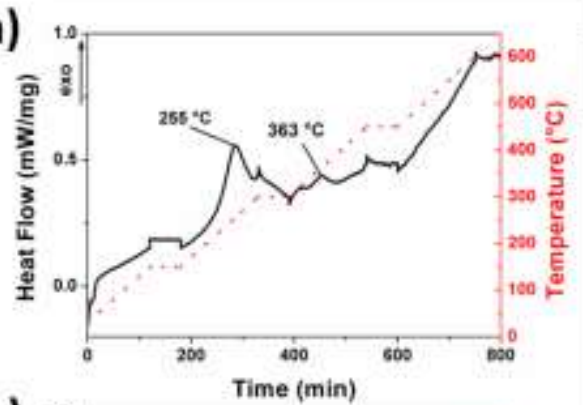

b)

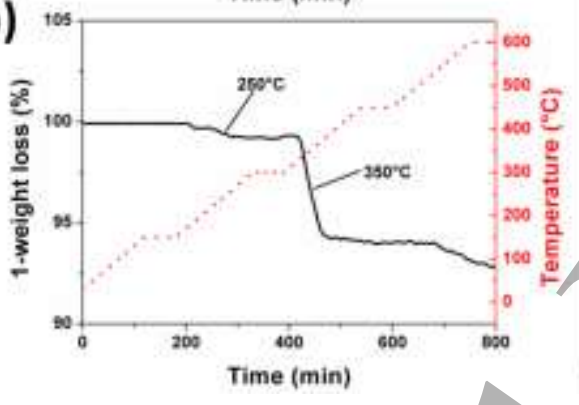

c)

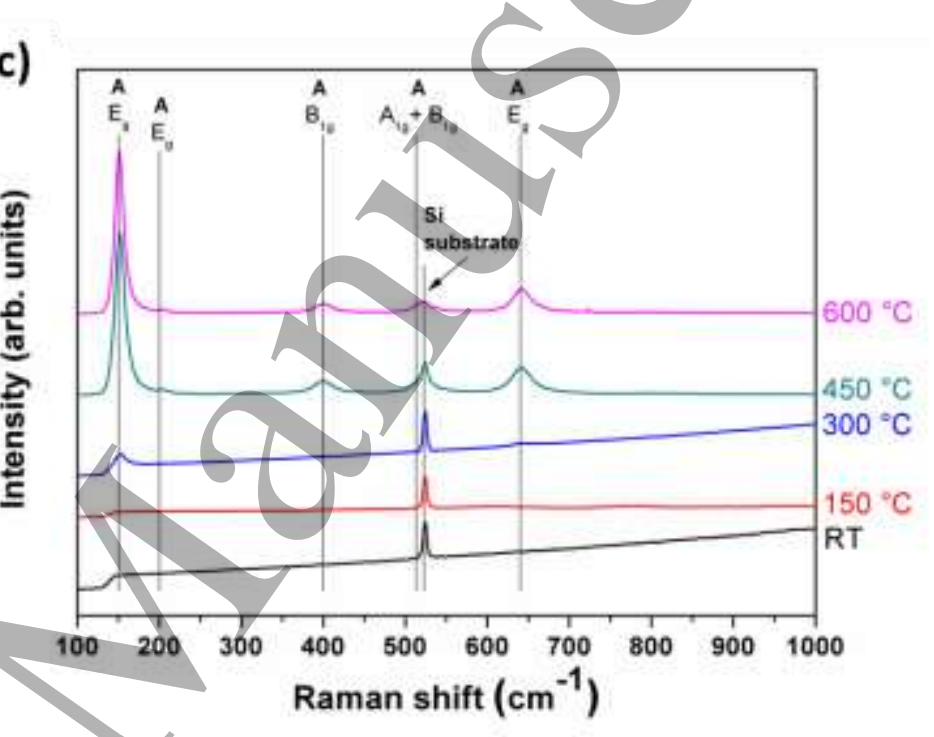

Figure 3. Thermal evolution of titania nanotubes (a) DSC thermogram, (b) TGA analysis and (c) Raman characterization of $\mathrm{TiO}_{2}$ nanotubes treated at different thermal annealing steps. The five resonances are related with anatase crystalline structure, showing the evolution of the crystallization process. The peak at $520 \mathrm{~cm}^{-1}$ is associated with the silicon substrate.

For mid temperature thermal processes, $\mathrm{TiO}_{2}$ crystallizes in the anatase phase, which is tetragonal (space group $\mathrm{I}_{1} /$ amd (No. 141)) with two formula units per unit cell and six Raman active modes $\left(\mathrm{A}_{1 \mathrm{~g}}+2 \mathrm{~B}_{1 \mathrm{~g}}+3 \mathrm{E}_{\mathrm{g}}\right)[40]$. Raman spectra acquired on single nanotubes are collected in Figure 3c, showing resonances at $144 \mathrm{~cm}^{-1}\left(\mathrm{E}_{\mathrm{g}}\right), 197 \mathrm{~cm}^{-1}\left(\mathrm{E}_{\mathrm{g}}\right), 399 \mathrm{~cm}^{-1}\left(\mathrm{~B}_{\mathrm{gg}}\right), 516 \mathrm{~cm}^{-1}\left(\mathrm{~A}_{1 \mathrm{~g}}+\mathrm{B}_{\mathrm{gg}}\right)$, and $639 \mathrm{~cm}^{-1}$ $\left(E_{g}\right)$. The crystallization of the structure in the anatase phase has an onset for a temperature lower 
than $300{ }^{\circ} \mathrm{C}$. The peak profile at $144 \mathrm{~cm}^{-1}$ becomes sharper during thermal treatment, witnessing the evolution of the crystallinity of the nanotubular structure and the crystalline domains size increase. No rutile phase is revealed for the performed treatment. This result is in agreement with previous findings[41] that evidenced the formation of rutile nanocrystal for temperature around $500{ }^{\circ} \mathrm{C}$, starting at the interfacial region between nanotubes and growth substrate, for tubular structure synthesized with ethylene glycol based electrolytes. In our case, since the crystallization occurs for single nanotubes or bundles of few nanotubes already detached from the growth substrate, the crystallization dynamics is slower, and rutile formation is expected to occur for temperature higher than $600^{\circ} \mathrm{C}$.

High resolution TEM (HRTEM) imaging and related analysis, which gives more detailed information on the crystal evolution of the individual titanium dioxide nanotubes, showed result in agreement with what reported above. The structural evolution of $\mathrm{TiO}_{2}$ amorphous nanotubes (NTs) vs. temperature was studied by HRTEM, using an ex situ approach with the aim of assessing the detailed structural evolution of the sample caused by heating performed in air (see Methods for details). This choice was preferred to the in situ heating approach of TEM experiments, because it granted a straightforward comparison to the above presented characterizations despite its shortcomings, namely the increased stress caused to the thin film of the in situ TEM MEMS and the gradual accumulation of external carbonaceous layer due to the contamination occurring during the heating in air and over the whole sample surface. This additional layer reacted when exposed to the electron beam and accumulated at the border of the areas investigated by HRTEM (as shown by the darker zones in Figure $4 b, c)$, but did not affect in a major way the possibility to carry on the structural analysis of the NTs.

The first evidence of structural evolution was observed after the sample was heated to $150^{\circ} \mathrm{C}$, with a minor number of crystalline seeds appearing within the overall amorphous NTs. The seeds were generally small-sized $(2 \div 3 \mathrm{~nm}$-wide), seldom reaching $10 \mathrm{~nm}$. All the seeds displayed monocrystalline features, with interplanar distances and related angular relationships obtained by 
HRTEM analysis being compatible with anatase (JCPDS Card No 84-1286, Figure 4d). Heating to $300^{\circ} \mathrm{C}$ did not cause major variations in the size of the seeds, although a texturing of the NTs could be observed. However, HRTEM analysis showed that at this stage the small (i.e. $2 \div 3 \mathrm{~nm}$ ) and big (i.e. $10 \mathrm{~nm}$ ) seeds were still monocrystalline but exhibited diverse interplanar distances and angular relationships, with the structural features of the larger seeds being typical of the anatase, and those of the smaller ones being consistent with the presence of brookite (JCPDS Card No 76-1937 Figure 4e). Heating up to $450^{\circ} \mathrm{C}$ determined a ubiquitous crystallization of the NTs. The increase in temperature led to the formation of extended crystalline domains, several tens of $\mathrm{nm}$ wide, paired with heavily inhomogeneous regions featuring several small crystalline domains. Structural analysis confirmed the presence of anatase and brookite in both types of crystalline domains (small and extended). Then, despite each phase prevailing over the other one on a local scale, neither of them could be indicated as the primary phase on a general term (Figure 4f). However, given the intrinsically averaged nature of the Raman technique, the clear presence of the sole anatase vibrational peaks indicates that anatase is indeed the primary phase at $300^{\circ} \mathrm{C}$.

The chemico-physical characterization performed on individual titanium dioxide nanotubes confirmed that their nanomechanical properties are strongly dependent on their crystal evolution upon thermal treatment. The almost linearly increase of the Young's modulus can be ascribable to two phases. Below $300^{\circ} \mathrm{C}$ the increasing of elastic modulus is mainly related to the thermal decomposition of chemical residual from the synthesis batch (mainly glycolated species) and surface trapped water evaporation. These processes harden the nanotubes and thus cause an increasing of the resonance frequency. HRTEM analysis also shows the formation of few small crystalline seeds $(2-3 \mathrm{~nm})$ which, given their scarcity, do not impact the overall amorphous nature of the nanotubes. Above $300^{\circ} \mathrm{C}$ the stiffening of the nanotubes is ascribable firstly to the dehydroxylation of $\mathrm{TiOH}$ to $\mathrm{TiO}_{2}$ and then to the crystallization of the titanium dioxide from the amorphous form into anatase (with a very low content of brookite) which increases according with the temperature of the thermal treatment. 

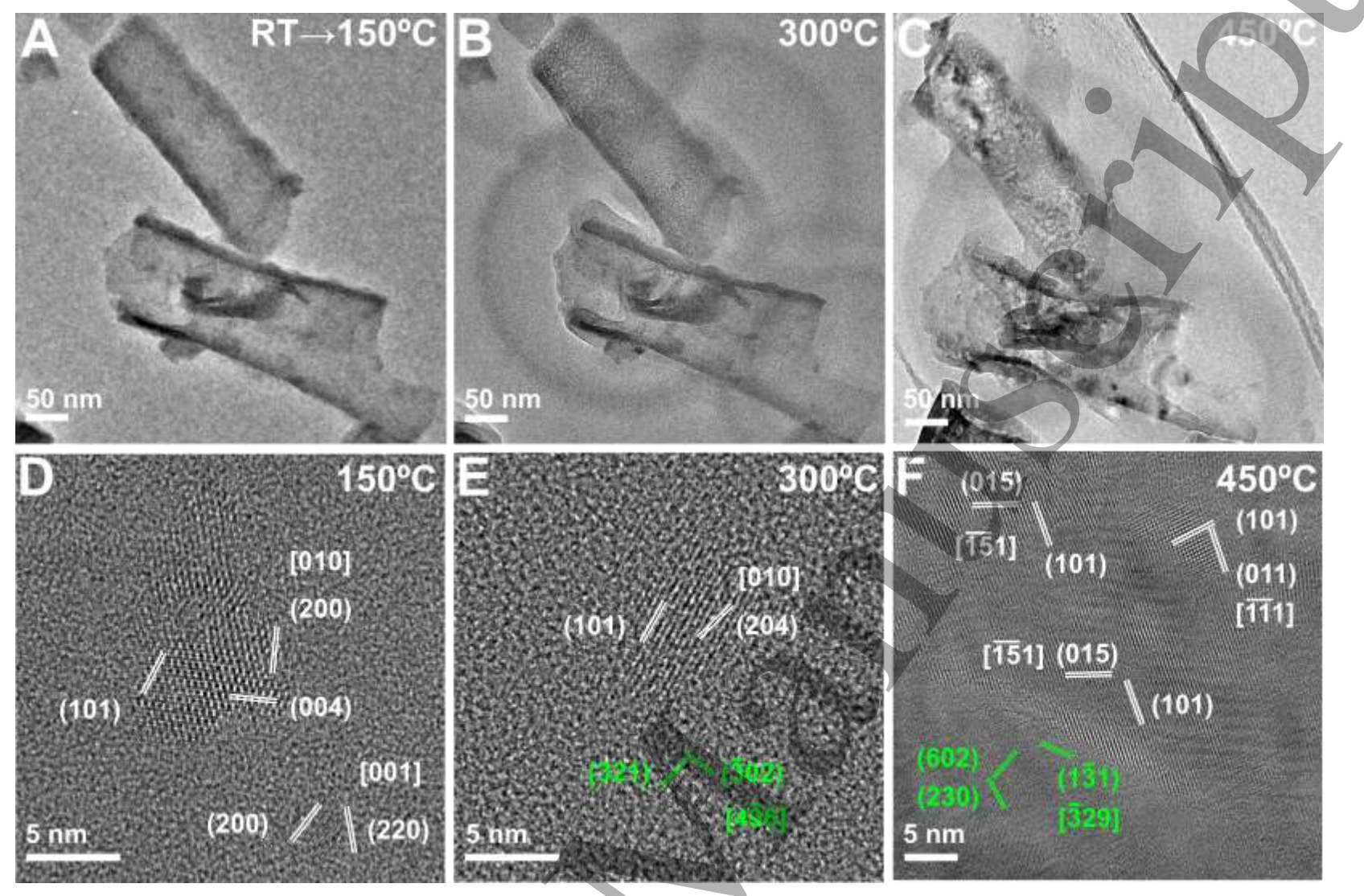

Figure 4 Crystallographic evolution of single $\mathrm{TiO}_{2}$ nanotubes. (a-c) Low magnification TEM images showcasing the NTs evolution vs. $\mathrm{T}$ of the $\mathrm{TiO} 2 \mathrm{NTs}$ after ex situ heating from RT to $150^{\circ} \mathrm{C}$ (a), $300^{\circ} \mathrm{C}(\mathrm{b})$ and $450^{\circ} \mathrm{C}(\mathrm{c})$; $\mathrm{HRTEM}$ images of representative $\mathrm{TiO} 2 \mathrm{NTs}$ after ex situ heating up to $150^{\circ} \mathrm{C}$ (d), $300^{\circ} \mathrm{C}$ (e) and $450^{\circ} \mathrm{C}$ (f). The structural information on crystalline domains of anatase and brookite are indicated in white and green color, respectively.

\section{CONCLUSION}

Nanomechanical properties of individual titanium dioxide nanotubes were studied with a noninvasive indirect approach based on modal vibration response analysis. From the measure of the resonance frequency modes of the suspended nanotubes it was possible to obtain the Young's modulus, which corresponds to $57 \mathrm{GPa}$ for as synthesized nanostructures. Upon thermal treatment the Young's modulus was found to linearly increase up to $105 \mathrm{GPa}$ for $600^{\circ} \mathrm{C}$. Chemico-physical 
characterizations evidences that below $300^{\circ} \mathrm{C}$ the stiffening of the nanotubes is induced by organic compounds removal trapped from the synthesis process. Above it, the increasing of Young's modulus is determined by the crystallization of the $\mathrm{TiO}_{2}$ nanotubes from the amorphous phase to the anatase one. These results give a deeper comprehension of the mechanical properties and crystallization evolution of individual titanium dioxide nanotubes extrapolated from their standard arrayed architecture. Considering the growing application of nanomaterials, this work provides new insights for improved design and understanding of single nanostructure devices.

\section{CONFLICTS OF INTEREST}

The authors declare no competing financial interests.

\section{REFERENCES}

[1] Gong D, Grimes C A, Varghese O K, Hu W, Singh R S, Chen Z and Dickey E C 2001 Titanium oxide nanotube arrays prepared by anodic oxidation J. Mater. Res. 16 3331-4

[2] Bella F, Lamberti A, Bianco S, Tresso E, Gerbaldi C and Pirri C F 2016 Floating, Flexible Polymeric Dye-Sensitized Solar-Cell Architecture: The Way of Near-Future Photovoltaics Advanced Materials Technologies 11600002

[3] Lamberti A, Sacco A, Bianco S, Manfredi D, Cappelluti F, Hernandez S, Quaglio M and Pirri C F 2013 Charge transport improvement employing $\mathrm{TiO}_{2}$ nanotube arrays as front-side illuminated dyesensitized solar cell photoanodes PCCP 15 2596-602

[4] Shankar K, Mor G K, Prakasam H E, Varghese O K and Grimes C A 2007 Self-assembled hybrid polymer-TiO 2 nanotube array heterojunction solar cells Langmuir 23 12445-9

[5] Wang X, Li Z, Xu W, Kulkarni S A, Batabyal S K, Zhang S, Cao A and Wong L H $2015 \mathrm{TiO}_{2}$ nanotube arrays based flexible perovskite solar cells with transparent carbon nanotube electrode Nano Energy 11 728-35

[6] Gui Q, Xu Z, Zhang H, Cheng C, Zhu X, Yin M, Song Y, Lu L, Chen X and Li D 2014 Enhanced photoelectrochemical water splitting performance of anodic $\mathrm{TiO}_{2}$ Nanotube arrays by surface passivation ACS Applied Materials and Interfaces 6 17053-8

[7] Hernández S, Hidalgo D, Sacco A, Chiodoni A, Lamberti A, Cauda V, Tresso E and Saracco G 2015 Comparison of photocatalytic and transport properties of $\mathrm{TiO}_{2}$ and $\mathrm{ZnO}$ nanostructures for solardriven water splitting PCCP 17 7775-86

[8] Lamberti A, Garino N, Sacco A, Bianco S, Chiodoni A and Gerbaldi C 2015 As-grown vertically aligned amorphous $\mathrm{TiO}_{2}$ nanotube arrays as high-rate Li-based micro-battery anodes with improved long-term performance Electrochim. Acta 151 222-9

[9] Lu X, Wang G, Zhai T, Yu M, Gan J, Tong Y and Li Y 2012 Hydrogenated $\mathrm{TiO}_{2}$ nanotube arrays for supercapacitors Nano Lett. 12 1690-6 
[10] Zou J, Zhang Q, Huang K and Marzari N 2010 Ultraviolet photodetectors based on anodic TiO2 nanotube arrays Journal of Physical Chemistry C 114 10725-9

[11] Lamberti A, Virga A, Chiadò A, Chiodoni A, Bejtka K, Rivolo P and Giorgis F 2015 Ultrasensitive Agcoated $\mathrm{TiO}_{2}$ nanotube arrays for flexible SERS-based optofluidic devices Journal of Materials Chemistry C 3 6868-75

[12] Mor G K, Carvalho M A, Varghese O K, Pishko M V and Grimes C A 2004 A room-temperature TiO2nanotube hydrogen sensor able to self-clean photoactively from environmental contamination $J$. Mater. Res. 19 628-34

[13] Berger S, Ghicov A, Nah Y C and Schmuki P 2009 Transparent TiO2 nanotube electrodes via thin layer anodization: Fabrication and use in electrochromic devices Langmuir 25 4841-4

[14] Liu Z, Zhang X, Nishimoto S, Jin M, Tryk D A, Murakami T and Fujishima A 2008 Highly ordered TiO2 nanotube arrays with controllable length for photoelectrocatalytic degradation of phenol Journal of Physical Chemistry C 112 253-9

[15] Conti D, Lamberti A, Porro S, Rivolo P, Chiolerio A, Pirri C F and Ricciardi C 2016 Memristive behaviour in poly-acrylic acid coated $\mathrm{TiO}_{2}$ nanotube arrays Nanotechnology 27485208

[16] Park J, Bauer S, Von Der Mark K and Schmuki P 2007 Nanosize and vitality: TiO2 nanotube diameter directs cell fate Nano Lett. 7 1686-91

[17] Chiarello G L, Zuliani A, Ceresoli D, Martinazzo R and Selli E 2016 Exploiting the Photonic Crystal Properties of $\mathrm{TiO}_{2}$ Nanotube Arrays to Enhance Photocatalytic Hydrogen Production ACS Catalysis 6 1345-53

[18] Roy P, Berger S and Schmuki P $2011 \mathrm{TiO}_{2}$ nanotubes: Synthesis and applications Angewandte Chemie - International Edition 50 2904-39

[19] Yu J, Dai G and Cheng B 2010 Effect of crystallization methods on morphology and photocatalytic activity of anodized TiO2 nanotube array films Journal of Physical Chemistry C 114 19378-85

[20] Lamberti A, Chiodoni A, Shahzad N, Bianco S, Quaglio M and Pirri C F 2015 Ultrafast roomtemperature crystallization of $\mathrm{TiO}_{2}$ nanotubes exploiting water-vapor treatment Scientific Reports $\mathbf{5}$ 7808

[21] Kim Y H, Heo J S, Kim T H, Park S, Yoon M H, Kim J, Oh M S, Yi G R, Noh Y Y and Park S K 2012 Flexible metal-oxide devices made by room-temperature photochemical activation of sol-gel films Nature 489 128-32

[22] Bella F, Lamberti A, Sacco A, Bianco S, Chiodóni A and Bongiovanni R 2014 Novel electrode and electrolyte membranes: Towards flexible dye-sensitized solar cell combining vertically aligned $\mathrm{TiO}_{2}$ nanotube array and light-cured polymer network Journal of Membrane Science 470 125-31

[23] Lamberti A, Fontana M, Bianco S and Tresso E 2016 Flexible solid-state $\mathrm{Cu}_{x} \mathrm{O}$-based pseudosupercapacitor by thermal oxidation of copper foils Int. J. Hydrogen Energy 41 11700-8

[24] Li M, Mayer T S, Sioss J A, Keating C D and Bhiladvala R B 2007 Template-grown metal nanowires as resonators: Performance and characterization of dissipative and elastic properties Nano Lett. 7 3281-4

[25] Eom K, Park H S, Yoon D S and Kwon T 2011 Nanomechanical resonators and their applications in biological/chemical detection: Nanomechanics principles Physics Reports 503 115-63

[26] Xu Y N, Liu M N, Wang M C, Oloyede A, Bell J M and Yan C 2015 Nanoindentation study of the mechanical behavior of $\mathrm{TiO}_{2}$ nanotube arrays J. Appl. Phys. 118145301

[27] Santos L S, Oliveira N T C, Lepienski C M, Marino C E B and Kuromoto N K 2014 Elastic modulus evaluation of titania nanotubes obtained by anodic oxidation Revista Materia 19 33-9

[28] Crawford G A, Chawla N, Das K, Bose S and Bandyopadhyay A 2007 Microstructure and deformation behavior of biocompatible TiO2 nanotubes on titanium substrate Acta Biomaterialia 3 359-67

[29] Chang W Y, Fang T H, Chiu Z W, Hsiao Y J and Ji L W 2011 Nanomechanical properties of array TiO 2 nanotubes Microporous Mesoporous Mater. 145 87-92

[30] Hirakata H, Ito K, Yonezu A, Tsuchiya H, Fujimoto S and Minoshima K 2010 Strength of selforganized TiO2 nanotube arrays Acta Mater. 58 4956-67

[31] Munirathinam B and Neelakantan L 2016 Role of crystallinity on the nanomechanical and electrochemical properties of $\mathrm{TiO}_{2}$ nanotubes J. Electroanal. Chem. 770 73-83 
[32] Shokuhfar T, Arumugam G K, Heiden P A, Yassar R S and Friedrich C 2009 Direct compressive measurements of individual titanium dioxide nanotubes ACS Nano 3 3098-102

[33] Kang S H, Fang T H, Chen T H, Hsiao Y J, Hong Z H, Chuang C H and Riccobono L 2014 Size effect on mechanical properties of $\mathrm{TiO} 2$ capped nanotubes investigated using in situ transmission electron microscopy Microsystem Technologies 20 515-20

[34] Treacy M M J, Ebbesen T W and Gibson J M 1996 Exceptionally high Young's modulus observed for individual carbon nanotubes Nature 381 678-80

[35] Stassi S, Cauda V, Fiorilli S and Ricciardi C 2015 Surface area enhancement by mesoporous silica deposition on microcantilever sensors for small molecule detection Journal of Materials Chemistry C 3 12507-13

[36] Stassi S, Chiadò A, Calafiore G, Palmara G, Cabrini S and Ricciardi C 2017 Experimental evidence of Fano resonances in nanomechanical resonators Scientific Reports 71065

[37] Jiang X, Herricks T and Xia Y 2003 Monodispersed spherical colloids of titania: Synthesis, characterization, and crystallization Adv. Mater. 15 1205-9

[38] Oh H-J, Lee S, Lee B, Jeong Y and Chi C-S 2011 Surface characteristics and phase transformation of highly ordered TiO2 nanotubes Metals and Materials International 17613

[39] Del Ángel-Sánchez K, Vázquez-Cuchillo O, Salazar-Villanueva M, Sánchez-Ramírez J F, Cruz-López A and Aguilar-Elguezabal A 2011 Preparation, characterization and photocatalytic properties of $\mathrm{TiO}_{2}$ nanostructured spheres synthesized by the Sol-Gel method modified with ethylene glycol J. Sol-Gel Sci. Technol. 58 360-5

[40] Bersani D, Lottici P P and Ding X Z 1998 Phonon confinement effects in the Raman scattering by $\mathrm{TiO}_{2}$ nanocrystals Appl. Phys. Lett. 72 73-5

[41] Jarosz M, Syrek K, Kapusta-Kołodziej J, Mech J, Małek K, Hnida K, Łojewski T, Jaskuła M and Sulka G D 2015 Heat treatment effect on crystalline structure and photoelectrochemical properties of anodic $\mathrm{TiO}_{2}$ nanotube arrays formed in ethylene glycol and glycerol based electrolytes Journal of Physical Chemistry C 119 24182-91 